\title{
Guest Editorial for Special Issue on
}

Next-Generation Cold Supply Chain Management: Research, Applications and Challenges Guest editors:

A cold supply chain, also called a temperature-controlled supply chain, is a logistics and supply system that provides a series of facilities for maintaining ideal conditions for goods within a given temperature range, from the point of origin to the point of consumption. Cold supply chains are particularly used for food products. Typically, such supply chains face greater risks and uncertainties owing to issues such as product perishability, the wide variety of products delivered, multiple suppliers of raw materials, short shelf lives, stringent traceability and regulatory requirements, and greater supply chain distances - and thus more handling points and larger networks. This, in turn, creates higher risks of food waste and increases costs; there are also often health risks if spoiled goods end up on the market.

With the ever greater movement of perishable goods around the world, it is becoming important to consider the food supply chain more holistically, to include not only cultivation and food processing, but also areas such as packaging, handling, storage and distribution as well as the technologies used to monitor the entire chain. These processes result in more complex supply networks, and emphasise the central role played by logistics systems in the efficient and timely management of a cold supply chain, from 'farm to fork'. The management of a cold supply chain is multidisciplinary in nature (Raab, 2011), in that it requires an understanding of perishable food, agricultural produce or medicines, for instance, as categories of product typically distributed via cold supply chains, coupled with an awareness of the use of ICT applications, as well as knowledge of the mechanics of heat transfer and thermodynamics. Practitioners need such a holistic view of cold supply chains.

This special issue, "Next-Generation Cold Supply Chain Management: Research, Applications and Challenges", extends our understanding of the issues and challenges that are likely to be encountered when developing the next generation of cold logistics and supply chain operations. The origin of this special issue can be credited to the 21 st International Symposium on Logistics (ISL), hosted by National Kaohsiung First University of Science \& Technology, in Kaohsiung, Taiwan, along with the University of Nottingham, China and UK, in July 2016. During this event, a focused workshop on cold supply chains was held, with 
considerable debate amongst participants from academia and industry on some of the challenges faced by the sector around the globe. As a follow-up, the editors of this special issue were invited by Emerald to develop a call for papers on cold supply chains, which was made public in the autumn of 2016, with a submission deadline set for the end of January 2017. Of the 21 papers submitted, 19 were subjected to blinded peer review, which eventually led to the selection of the 8 papers in this issue.

The first paper included in our special issue, by Kashav, Cerchione, Singh, Centobelli and Shabani (2018) is titled "Food cold chain management: From a structured literature review to a conceptual framework and research agenda". This paper argues that post-harvest food waste amongst the world's two most heavily populated countries, namely China and India, remains alarmingly high, at least in part due to inefficiencies in their cold supply chains. Against this backdrop, the paper critically analyses and reviews 89 published articles with a view to formulating a conceptual framework encapsulating various dimensions of food cold supply chains, such as infrastructure, integration, stakeholders' interest, value addition, partners' performance and overall performance. The proposed conceptual framework could serve as a basis for further empirical research.

Building on the theme of the literature review, Bremer (2018), in the issue's second paper, entitled "Towards a reference model for the cold chain", argues that the business of managing supply chains is deficient because the unique requirements of the cold supply chain have not been adequately captured, especially the specific nature of temperaturesensitive perishable goods. Hence a reference model deploying an object-oriented modelling approach is derived and synthesised. The classes within the object model are highly interconnected, covering the key dimensions of cold supply chains, i.e. perishability of products, information technology, infrastructure/equipment and regulatory aspects. The proposed reference model can be seen as a step towards the development of an overarching holistic standardised design and as an analysis tool box for the planning of cold supply chains. However, the proposed reference model requires further empirical research to enhance its applicability and validity.

The third paper, by Chaudhuri, Dukovska-Popovska, Subramanian, Chan and Bai (2018), is titled "Decision-making in cold chain logistics using data analytics: A literature review". The underlying premise of this paper is that there is little evidence on how data can be captured 
effectively for decision-making in relation to extended cold supply chains, especially for fish and meat products. The paper argues that there is a need to better understand data capture and its role in decision-making, not just for distribution but across the entire cold supply chain, from post-harvest to processing to distribution and finally to retail. A total of 38 articles published over the last 15 years are reviewed to develop an overview of several technologies used to capture and share data across the supply chain to support decisionmaking. The main conclusion of this study is that there is a need to develop real-time data capture and analytics approaches to preserve the integrity of goods and to minimise waste. Some of these strategies or decisions may involve dynamic reconfiguration of cold supply chain.

Numerous studies have highlighted the importance of the last mile, as it involves the final delivery of products to customers and is currently one of the most expensive, least efficient and most polluting sections of the logistics chain. This is the theme of the fourth paper, by Hsiao, Chen, Lu and Chin (2018), entitled "Last-mile distribution planning for fruit-andvegetable cold chains", which has a specific focus on the delivery of perishable products (i.e. fresh fruits and vegetables). The problem is formulated as a vehicle routing problem with time windows (VRPTW). A genetic algorithm is deployed as a technique to solve the problem with multiple perishable products. Factors like fleet size, vehicle routing sequence, various requirements for quality levels from customers, and optimal temperature settings for product storage in multi-item, multi-temperature vehicles are taken into account. The findings indicate that the various customer requirements can be fulfilled with due attention to cost.

The theme of optimisation is continued in the fifth paper, by Chen, Lu and Liu (2018), entitled "Optimal consolidation of fresh agricultural products in a multi-temperature joint distribution system". The underlying rationale is that logistics service providers are keen to maintain competitiveness and at the same time deliver fresh fruits and vegetables to customers who demand timely delivery of small and diverse shipments in food cold supply chains. An optimal consolidation problem for fresh agricultural products (e.g. fruits and vegetables) in a multi-temperature joint distribution system is considered to address the unique challenges posed by customers. An integer programming optimisation model is developed, and evaluated using numerical examples, to consolidate a set of agricultural shipments with different storage requirements. The paper argues that the formulated model 
can minimise the consolidation cost and the loss of product value due to a reduction in shelf life after consolidation.

The sixth paper, by Guo, Wu and Chen (2018), is titled "Over- and under-estimation of risks and counteractive adjustment for cold chain operations: A prospect theory perspective". Smaller, more frequent and different temperature-sensitive e-commerce orders are growing, as is the requirement for product freshness. This has a knock-on effect on temperature monitoring and control mechanisms, as these are viewed as a major source of risk, and so need to be effectively managed. This research investigates decision-makers' attitudes to risk and assessment bias in different contexts of cold supply chains, and especially whether and how sociodemographic factors influence a practitioner's risk perception and assessment. The authors develop, on the basis of cumulative prospect theory (CPT), a model of how participants evaluate the risks of different decisions made under various levels of probability and severity of loss. The findings indicate that factors such as gender, job familiarity and confidentiality significantly influence the risk attitudes and subjective probability weightings of the respondents. The authors argue that, in practice, consideration needs to be given to more flexible attitudes to risk and subjective judgement when deciding risk-mitigation strategies.

The seventh paper, by Ali, Nagalingam and Gurd (2018), is titled "A resilience model for cold chain logistics of perishable products". The paper argues that existing studies on resilience build on normative, conceptual or silo approaches, and consequently an integrative approach to cold chain logistics risks (CCLRs) and resilience is lacking. The paper aims to bridge the current research gap by developing a model, based on broad empirical evidence, of the interplay between CCLRs, resilience and firm performance in perishable-product supply chains (PPSCs). It attempts to answer the following three questions. (a) What are the specific CCLRs and resources/capabilities required to build resilient logistics operations by PPSCs? (b) How do CCLRs impact on firms' performance? (c) How does supply chain resilience influence this relationship? Deploying a mixed-methods approach (qualitative and quantitative), the analysis of the findings is framed within the context of contingency-and resource-based theory. The findings indicate that there are four significant sources of CCLRs and that six types of resources are used to build resilience. In contrast, the theoretical framework suggests that resilience is a moderator in the negative relationship between CCLRs and performance. 
The final paper in this special issue, by Gligor, Gligor, Holcomb and Bozkurt (2018), is titled "The obstacles to cold chain implementation in developing countries: Insights from Vietnam". Their basic argument is that whilst many studies have recognised the enormity of food wastage and limited cold chain capability in developing countries, few studies have explored the underlying reasons for this. Hence they pose the following research question: What are the obstacles that impede the implementation of cold supply chains in developing countries? Grounded theory, coupled with in-depth interviews with Vietnamese managers and secondary data, were used to study this issue. Their empirical work is based on two sectors, namely fruit and vegetables, and milk and dairy products. Ten major obstacles are identified. These include: lack of expertise; lack of national-level quality and safety-control measures; supply chain density; deficient infrastructure and information systems; costly installation and operation of cold chains; deficiencies in training and standardisation; lack of government support; and social norms. An attempt is made to frame their findings with in a theoretical context.

While all eight papers explore different aspects of the cold supply chain, four major themes emerge. Firstly, there is no agreed and accepted conceptual framework and/or reference model which academics and practitioners working in the sector can use. Despite the existence of a plethora of conceptual/reference models in other areas, cold supply chains have not received similar attention. Thus cold supply chains are a fertile territory for further work.

Secondly, extensive expertise in the area of modelling and optimisation built over the last few decades could potentially be leveraged for cold supply chains. In fact, all segments of the extended cold supply chain can capitalise on this expertise to enhance their operations, irrespective of whether they are farmers, storage facilities, food processing plants, retailers or logistics service providers, etc. The prime focus, however, should be on how to minimise waste, reduce carbon emissions, maintain the freshness of products and, above all, minimise the cost of operations (Gallo et al., 2017).

Thirdly, risk and resilience of supply chains is increasingly gaining importance due to the high degree of uncertainty and vulnerability associated with perishable goods - be it due to climate change or to inadequacies in operations and/or in capabilities. Supply chains operating at low temperature to deliver perishable goods, unlike those working at ambient 
temperatures, are more prone or susceptible to natural disasters or environmental change or systems failure (World Courier, 2017). Pre- and post-incident impact resilience requires careful attention during the designing and configuring cold supply chains. Existing risk and resilience models require further development, and then testing and validating within the context of cold supply chains.

Fourthly, further empirical studies are required that focus on the strategic and operational implications of implementation of cold supply chains. The particular problems faced for different goods are likely to be specific to both country and context. For example, during winter in countries like Russia, Finland or Norway, the outside temperature may be lower than desired for certain perishable goods, and therefore the challenges are reversed (i.e. 'heating up') say in comparison to the Gulf states (Markmann, 2014). In countries where infrastructure such as electricity grids, roads and storage facilities is not well constructed the obstacles to the implementation of cold supply chains are insurmountable, at least in the short term (Markmann, 2014). The problems are exacerbated if the workforce is inadequately equipped or trained to handle modern cold chain solutions. Thus, any generic cold chain implementation framework or model will have to be highly customisable to cater for different contexts and country-specific scenarios.

Digitisation is another dimension which is likely to feature significantly in the evolution of next-generation cold supply chains. The Internet of Things (IOT) is being increasingly deployed as a result of the longer battery life, lower price and smaller size of such appliances. For example, with NB-loT (narrow-band loT) networks, terminals can transmit temperature, location and status to an loT platform in real time (Advantech, 2018; Militano et al., 2017). Wireless technology enables constant monitoring of temperature whilst cargo is on the move (Advantech, 2018). Besides monitoring, devices can be controlled with commands via an loT platform to ensure that goods are under strict and proper temperature control. Carbon-dioxide emission reduction, distribution routing and product allocation can also utilise loT to achieve optimal operational performance. Unfortunately, no papers were received on digitisation for this special issue, but we believe that the whole domain of digitisation and associated technologies requires a constructive debate on the links between digitisation and the integrity of cold supply chains. 
Proper control of temperature and humidity for perishable goods along the entire cold chain is critical. Any excursion in temperature is of concern in relation to product quality (World Courier, 2017), and, if sustained, such excursion can lead to problems with, for instance, the growth of microorganisms and VBN (volatile basic nitrogen) (Raab, 2011; Tsai and Lin, 2018). Therefore preventing excursion as well as understanding the factors contributing to them (e.g., ignorant or untrained workers, system failures, lack of capacity) require further exploration (Tsai and Lin, 2018). These can be studied empirically or as optimisation models in distribution assignment, storage options, etc.

As was the case for digitisation, no papers on packaging were received. Packaging plays a crucial role in protecting products from outside disturbances as well as in maintaining the quality of perishable goods (Garcia-Arca et al., 2014). Tolerance of temperature excursions over longer periods, as well as delays in the appearance of temperature excursion can be achieved through proper packaging. Appropriate packaging can greatly increase the efficiency of cold supply chain operations and prolong the freshness of products, especially during modal transfers (Mohebi and Marquez, 2014). Thus, besides research into packaging materials, when studying topics like risks and resilience, packaging can be considered as an essential component to minimise risks and increase system resilience.

The role of regulations and standards deserves a mention as a closing observation. This is an evolving and complex field, especially within an international context where there are inconsistencies in rules, regulations for equipment, facilities and operations, across companies, cities and countries. For instance, in February 2017, BSI PAS 1018: 2017 came into effect - "Indirect, temperature-controlled refrigerated delivery services - land transport of refrigerated parcels with intermediate transfer" (British Standard Institute, 2017). This international standard was mainly for parcel delivery and was planned to be promoted to an ISO standard in 2-4 years. The first author of the editorial of this special issue was invited to contribute to a meeting of the steering committee. However, PAS 1018 is limited to parcel delivery and is appropriate for $\mathrm{C} 2 \mathrm{C}$ and $\mathrm{B} 2 \mathrm{C}$ services, not B2B services, and yet because B2B usually requires stricter regulations there is an even higher demand for international standards. Research should be undertaken on the classification and evaluation of the standards related to cold supply chains to provide further insights. 


\section{References}

Advantech (2018), "Wireless IoT sensing solutions - Modularized and ready-to-use solutions / high adaptability for loT sensing", Advantech Catalogues, available at: http://advcloudfiles.advantech.com/ecatalog/2017/09071038.pdf (accessed 15 May 2018).

Ali, I., Nagalingam, S., Gurd, B. (2018), “A resilience model for cold chain logistics of perishable products", International Journal of Logistics Management, Vol. 29, No. 3,

Bremer, P. (2018), "Towards a reference model for the cold chain", International Journal of Logistics Management, Vol. 29, No. 3,

British Standard Institute (2017), PAS 1018:2017 Indirect, temperature-controlled refrigerated delivery services - land transport of refrigerated parcels with intermediate transfer, available at: https://www.bsigroup.com/en-GB/about-bsi/media-centre/pressreleases/2017/march/Specification-for-the-transport-of-chilled-and-frozen-parcelslaunched/ (accessed on 15 May 2018).

Chaudhuri, A., Dukovska-Popovska, I., Subramanian, N., Chan, H.K., Bai, R. (2018), “Decisionmaking in cold chain logistics using data analytics: a literature review", International Journal of Logistics Management, Vol. 29, No. 3,

Chen, M.-C., Lu, C.-C., Liu, Y.-C. (2018), “Optimal consolidation of fresh agricultural products in a multi-temperature joint distribution system", International Journal of Logistics Management, Vol. 29, No. 3,

Gallo, A., Accorsi, R., Baruffaldi, G. and Manzini, R. (2017), "Designing sustainable cold chains for long-range food distribution: energy-effective corridors on the Silk Road Belt", Sustainability, Vol. 9, pp. 1-20.

Garcia-Arca, J., Prado-Prado, C. and Garrido, A. (2014), “Packaging logistics: Promoting sustainable efficiency in supply chains", International Journal of Physical Distribution \& Logistics Management, Vol. 44 No. 4, pp. 325-346.

Gligor, D., Gligor, N., Holcomb, M., Bozkurt, S. (2018), “Distinguishing between the concepts of supply chain agility and resilience: A multidisciplinary literature review", International Journal of Logistics Management, Vol. 29, No. 3, 
Guo, S.-M., Wu, T., Chen, Y. (2018), "Over- and under-estimation of risks and counteractive adjustment for cold chain operations: A prospect theory perspective", International Journal of Logistics Management, Vol. 29, No. 3,

Hsiao, Y.-H., Chen, M.-C., Lu, K.-Y., Chin, C.-L. (2018), "Last-mile distribution planning for fruit-and-vegetable cold chains", International Journal of Logistics Management, Vol. 29, No. 3,

Kashav, S., Cerchione, R., Singh, R., Centobelli, P., Shabani, A. (2018), “Food cold chain management: from a structured literature review to a conceptual framework and research agenda", International Journal of Logistics Management, Vol. 29, No. 3,

Markmann, N. (2014), "Customizing the cold chain", AmerisourceBergen White Papers, available at: https://www.worldcourier.com/insights /customizing\%20the\%20cold\%20chain (accessed on 15 May 2018).

Militano, L., Orsino, A., Arantiti, G. and lera, A. (2017), “NB-loT for D2D-enhanced content

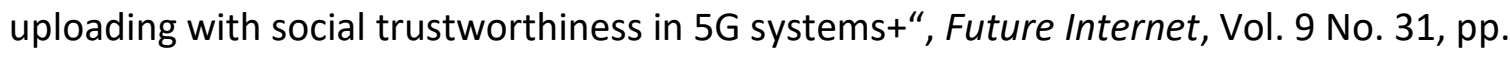
1-14.

Mohebi, E. and Marquez, L. (2014), "Intelligent packaging in meat industry: An overview of existing solutions", Journal of Food Science and Technology, Vol. 52 No. 7, pp. 3947-3964.

Raab, V. (2011), Assessment of Novel Temperature Monitoring Systems for Improving Cold Chain Management in Meat Supply Chains, PhD Dissertation, Institut für Tierwissenschaften, Germany.

Tsai, K.-M. and Lin, K.-S. (2018), "Studying the effect of ambient temperature exposure on refrigerated food quality and safety for sustainable food cold chains", in Xiaohong Liu (ed.), Environmental Sustainability in Asian Logistics and Supply Chains, Springer, Singapore.

World Courier (2017), "Six steps for reducing the risks of temperature excursion", AmerisourceBergen White Papers, available at: https://www.worldcourier.com/insights/six-steps-for-reducing-the-risks-oftemperature-excursion (accessed on 15 May 2018) 